\title{
The Mednyi Arctic foxes: treating a population imperilled by disease
}

\author{
M. Goltsman, E. P. Kruchenkova and D. W. Macdonald
}

By the early 1990s only 90 individuals of the endangered Arctic fox subspecies Alopex lagopus semenovi, remained. These few survivors are confined to Mednyi Island, part of the Commander Islands chain. The formerly abundant population crashed in the mid-1970s and has never recovered from only 10-15 per cent of its former numbers. In 1983 the Mednyi Island foxes were listed in the Russian Red Data Book. Their demise coincided with the arrival of mange, introduced by seafaring trappers and caused by the mite Otodectes cynotis, which was associated with devastating cub mortality. In 1994, in a unique intervention, we sought to save the population by treating cubs with antiparasitic drugs. That summer, mortality was reduced. A census in 1995 suggested that over-winter survival was at least no worse, although it is too soon to judge whether this intervention can be a route to population recovery.

The foxes who were found there in uncountable numbers became more and more daring and aggressive... . They stole our baggage, gnawed soles, boots, trousers, coats... . We became so embittered with them that we killed them, young and old, played dirty tricks on them and tortured them in the most cruel ways. In the course of my stay on the island I have killed more than 200 of these filthy creatures. On the third day I killed more than 70 foxes in 3 hours with an axe, and we made the roof of our house out of their skins.

Georg Steller, 10 November 1741.

\section{Introduction}

Two of the three subspecies of Arctic fox in Russia exist only as small, endemic populations inhabiting the Commander Islands: Alopex lagopus beringensis Merriam 1902 on Bering Island, and A. l. semenovi Ognev 1931 on Mednyi Island (Geptner and Naumov, 1967). A. l. semenovi has been listed as Endangered in the Russian Red Data Book since 1982.
Commander Islands' Arctic foxes are unusual because of their evolutionary isolation and their social behaviour. The foxes have been isolated since the Pleistocene (Zalkin, 1944) and this isolation has occurred at the interface between North America and Asia, close to the route travelled by the first canids to migrate into Eurasia from America (Macdonald, 1992). They live at the southern edge of the Arctic fox's range, on volcanic islands (where the rocks are characterized by high levels of natural radiation; Shmidt, 1991), circumstances under which we might expect pronounced evolutionary change (Mayr, 1963; Wayne et al., 1991).

Mednyi Arctic foxes can live at very high densities - up to 1000-2000 animals, mostly confined to the coastline of an island only 186 $\mathrm{sq} \mathrm{km}$ in area - and this has profound consequences for their social behaviour, which is reflected in complicated family structures. For example, the foxes live in groups, in which some females breed and in which some nonbreeders act as helpers at the den, whereas others do not (Kruchenkova, Goltsman and Macdonald, unpubl. data). Enclaves of Mednyi foxes living at high densities are involved in almost continuous social contact, 
both within and between groups - a social milieu that is unusual among fox species, and among canids in general. Prolonged isolation and unusual circumstances have thus led not only to the formation of morphologically distinct subspecies, but also to intriguing ecological and behavioural adaptations.

The importance of Mednyi Arctic foxes is all the greater because small groups of Arctic foxes of alien subspecies were introduced to Bering Island earlier this century. Thus, the Mednyi population is the only remaining pristine subspecies on the Commander Islands. Furthermore, the Arctic fox is the only terrestrial carnivore on Mednyi and plays an important role in an unusual island ecosystem.

Here we document the past and present status of the Mednyi Arctic fox, and muster evidence that low population densities in the last 20 years are due to catastrophic cub mortality associated with mange. That decline offers a 'natural experiment' within which we seek to tackle questions concerning the relationships between the foxes and their food and why, for example, the foxes persist in living in groups when the decline in their population has left the survivors with a superfluity of food and little obvious constraint on dispersal. However, although the mange epidemic creates the opportunity to study many intriguing questions in fox biology, it also raises the spectre that the entire subspecies is imminently imperilled. Therefore, and finally, we describe our attempt, prompted by the conviction that the subspecies faces extinction, to reduce cub mortality by treating cubs with antiparasitic drugs. Such veterinary intervention, motivated by conservation, raises complicated ethical questions (e.g. Macdonald, 1995).

\section{Mednyi Island}

Mednyi Island lies within the Commander Islands State Nature Reserve, which was created in 1993. The Commander Islands are at the western end of the Aleutian Island Arc, $175 \mathrm{~km}$ east of Kamchatka between $55^{\circ} 25^{\prime}$ to

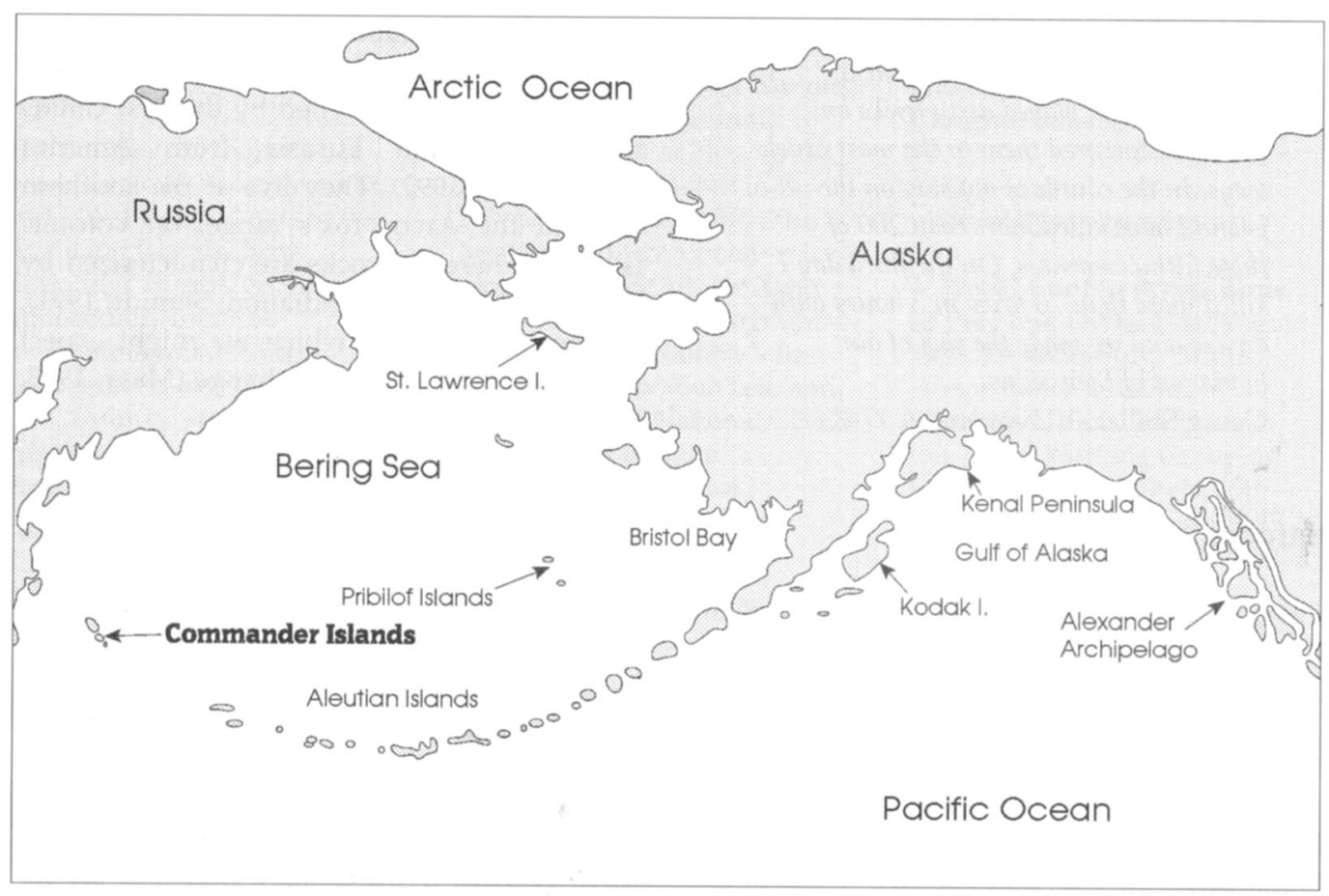

Figure 1. Map showing location of Commander Islands. 
$54^{\circ} 31^{\prime} \mathrm{N}$ and $165^{\circ} 04^{\prime}$ to $168^{\circ} 0^{\prime} \mathrm{E}$ in the Pacific Ocean, in the south of the Bering Sea (Figure 1). The Commander Islands' ecosystem is generally well preserved, but in the 250 years since the islands were discovered by Vitus Bering (1741), two endemic species have become extinct: Steller's sea cow Hydrodamalis gigas Zimmermann 1780, and Steller's cormorant Phalacrocorax perspicillatus Pallas 1748. Mednyi Island covers an area of $187 \mathrm{sq} \mathrm{km}$, is $53 \mathrm{~km}$ long and ranges in width from 0.35 to $7.5 \mathrm{~km}$. The mountains on Mednyi rise to 700 $\mathrm{m}$, and are covered with mountain tundra. Motor boat is the only means of rapid transportation or haulage around the island. There have been no permanent inhabitants since 1972 , but scientific expeditions work on the island each summer. Moreover, each summer the island is visited by traders (hunting fur seals on the south-eastern rookery) and by tourists.

\section{Historical status of Mednyi Arctic foxes}

When the Commander Islands were discovered in the eighteenth century, densities of Arctic foxes were extremely high. Steller (1793) described a tremendous abundance of foxes and recorded that on Bering Island he killed over 70 animals with an axe in 3 hours. From 1745 until 1785, 43,000 foxes were killed on the Commander Islands for their pelts (Iljina, 1950).

During the mid-nineteenth and early twentieth centuries an average of 700 foxes were caught for their fur on Mednyi Island each trapping season, although trapping was not conducted every year (Suvorov, 1912). For example, 1311 foxes were killed in 1886, 692 in 1888, and 975 in 1896. In 1913 an upper annual catch limit of 700 foxes was established on Mednyi.

From 1922 until 1962 a fur farm operated on Mednyi. Foxes were caught in live-traps during the trapping season and were held and fed in the traps throughout the remainder of the year. During this period fox numbers declined, but remained sufficiently high for the annual collection of more than $300-400$ foxes
(Iljina, 1950). In 1966, for example, 600 foxes were taken (Chelnokov, 1982). Fox trapping and farming on Mednyi stopped at the end of the 1960s and the settlement (up to 300 inhabitants) was disbanded in 1972 as part of a government policy, unconnected with fox trapping, to disband small settlements.

Annual summer surveys indicated that the fox population on Mednyi remained stable at about 600 until 1975 (S. Marakov, pers. comm.). The population was sufficiently large for Marakov to recommend to the Kamchatka administration that trapping be recommenced, with an annual cull of 200-300 foxes. This plan was not instigated. Between 1975 and 1977 there was a steep decline in population density (Naumov et al., 1981) as a result of a sharp increase in cub mortality. The severity of this decline is illustrated by numbers of foxes seen at a northern fur seal Callorhinus ursinus rookery in the south-east of Mednyi. Counts of foxes along a standard route through this rookery, which took several hours to complete, were conducted annually in July-August. The counts were conducted daily over 5 days and yielded maxima during one walk of 19-65 in 1966-1974, and 49 foxes in 1975. After 1976 the 5-day walks yielded just 1-4 foxes (Chelnokov, 1982 and pers. comm.).

Scrutiny by trappers and other visitors is such that there is no doubt that mange affected neither the pelt quality of adults nor the survival of cubs prior to 1976 . We suspect that Otodectes cynotis was then brought to the island on the dogs that accompany seafaring trappers. The cub disease was first noticed in 1976 (Ovsjanikov et al., 1982). By then fewer than 200 foxes survived on Mednyi Island, and by 1978 the population had declined to below 120 animals (Naumov et al., 1981). During regular summer counts over the last 17 years, population estimates have ranged from 60 to 100 (V. Sevostijanov, A. Zimenko, Yu. Artukhin and D. Rjazanov, pers. comms), and the population has not exceeded 10-15 per cent of pre-1975 levels. The density has, therefore, crashed from an estimated peak of $600-1500$ to a 1994 low of 90 animals. In the meantime, there has been no observable 
change in the resource base and no trapping.

Although this circumstantial evidence makes plausible the conclusion that otodectic mange was the cause of the cub mortality, we do have some doubts about this conclusion. This form of mange, ear canker, which is often considered rather hard to transmit, is not normally fatal, and it is puzzling that the cubs did not lose condition before dying. This raises the possibility that another pathogen is afflicting the foxes in parallel with the mange. We are mindful that parvovirus is also transmitted by dogs, persists for weeks in faeces, may show few signs and tends to kill young canids but not adults. Logistical and financial considerations have previously thwarted the efforts of the Russian veterinarians to test for parvovirus, and doing this is one of our priorities for the coming field season. However, it is noteworthy that many dying cubs repeatedly shook their heads - a recognized sign that canker mites had damaged their tympanic membranes and caused inflammation of the brain.

\section{Status in 1994}

Faced with this catastrophic decline, diagnosis of otodectic mange by Russian veterinarians and the realistic possibility of extinction, in 1994 we decided to intervene. This decision was taken on the grounds that the 15-year long depression in fox numbers could be attributed to no other cause than the introduction of canine disease, and such a small and fragmented population was imperilled by stochastic misadventure and possibly by the demographic and genetic hazards of small numbers. The precariousness of the breeding stock is illustrated by the demography of the 28 adults in our study subpopulation in 1976, of which 11 of 20 females lactated and the 28 cubs born suffered 96.4 per cent mortality, associated with mange. By 1978, 16 adults inhabited the study area and six of nine females lactated, 88.5 per cent of their 26 cubs succumbing to mange.

In 1994 we divided the island into northern and southern sectors, both to facilitate ecologi- cal comparisons between the two, and to provide both a treatment and non-treatment sample for our planned intervention to treat mange. Between 28 May and $28 \mathrm{July}$, one team carried out a census of adults and litters along transects throughout Mednyi. These transects were close to the shoreline, which is where the foxes are concentrated. Although not an exhaustive survey, the transect counts facilitated a comparison between the fox population density in the northern half of the island and that in the southern half of the island, where the second team also mapped in detail the abundance and distribution of foxes and traditional dens between 1 July and 2 September. In the southern sector (about $70 \mathrm{sq} \mathrm{km}$ ) some $55-60$ adults were monitored, organized as 14 families, of which all save one produced litters. A total of 58 cubs was produced by 18 lactating females (there were seven non-lactating females cohabiting with breeding females and a further five non-lactating females living singly). Intriguingly, despite a more than tenfold reduction in population density and copious food, these foxes still lived in territorial groups including non-breeding adults.

The transect counts revealed 13 adult foxes in the northern half of Mednyi and 26 in the southern half. Concluding that the number of foxes in the north was approximately half that in the south, we extrapolated from the detailed counts in the south to estimate the total population of foxes on Mednyi in 1994 at roughly 90 animals.

Sarcoptic mange Sarcoptes scabiei in red foxes Vulpes vulpes, can affect adults badly (e.g. Lindstrom and Morner, 1985; Danell and Hoernfeldt, 1987; Lindstrom et al., 1994). Interestingly, we have no evidence of mange affecting adult Mednyi Arctic foxes and, as mentioned above, otodectic mange is not normally lethal.

\section{Cub mortality}

Between May and September 1976 one of us (E.P.K.) monitored seven litters containing 28 cubs, and during August and early September 27 (96.4 per cent) of them died. Similarly, 


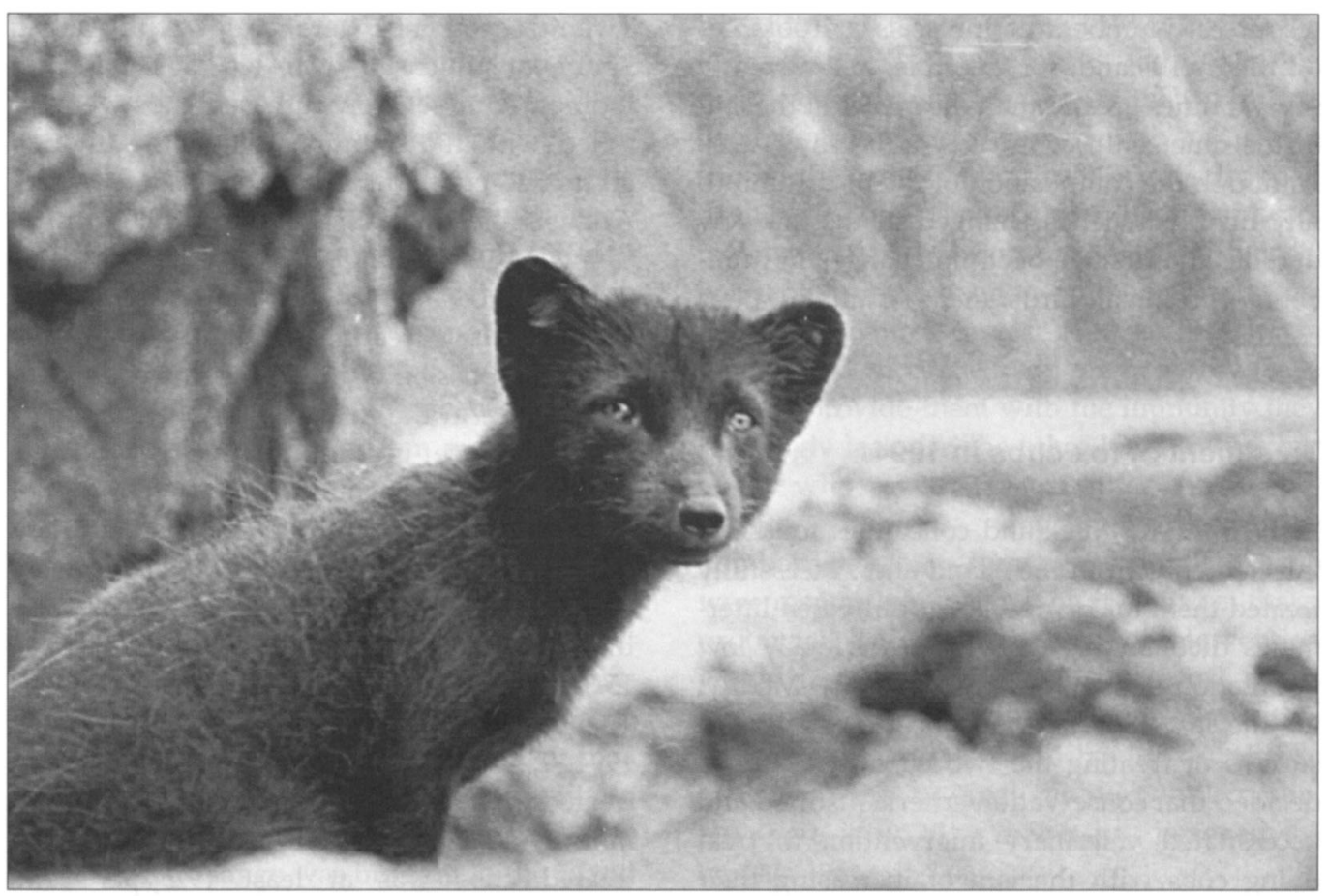

Arctic fox, observable at close quarters on Mednyi Island (M. Goltsman).

between June and August 1978 five litters containing 26 cubs were monitored, but in August 23 cubs ( 88.5 per cent) died. In both years most deaths occurred over a few days during August. All of these cubs were seriously afflicted with mange, resulting from infection by the mites Otodectes cynotis (Order Acari, Suborder Astigmata, Family Psoroptidae). The aetiology of the disease was the same in all of the five litters in which it could be traced. Bald patches of skin seething with the parasites appeared on cubs' bodies. These areas were typically situated around the auricle of the ear, on the top of the head, on the abdomen and in the inguinal (groin) region. The fur, especially in parasitized areas, was covered in a dust of sloughed dermal scales. Once parasites were apparent, the cub lost weight, frequently shook its head, and spent almost all of its time lying and huddling with other cubs. Death ensued within a week to 12 days of the first patent signs of mange. By early October 1976, only one cub survived from all infected litters; in 1978, only three of 26 cubs were alive by

(C) $1996 \mathrm{FFI}$, Oryx, 30 (4), 251-258 late August. Once one cub showed signs of mange, the entire litter was usually dead within 20-25 days. Dead cubs showed no signs of malnutrition and, prior to developing mange, all were in good condition. Indeed, food was conspicuously plentiful throughout the whelping season. The epizootic developed when colonial seabirds were nesting and when fur seals were pupping, providing abundant placentae and carcasses. On Mednyi Island, families of foxes specialize on different food resources, such as fish, seabird colonies, fur seal rookeries, or shoreline invertebrates such as sea urchins and amphipods (Kruchenkova, 1991). Although the particular feeding habitats of given individuals, for example those hunting amphipods versus those hunting seabirds, affected their parental behaviour and the energetics of foraging (Kruchenkova and Goltsman, 1994), this had no bearing on the prevalence or outcome of endoparasite infection.

There was no evidence that the population decline was linked to a decline in food 
resources. Numbers of fur seals at rookeries on Mednyi Island, for example, are currently several times greater than they were at the end of the nineteenth century (Vladimirov, 1991). Although the composition of the bird community on Mednyi has changed in the last few decades, there have been no changes in numbers of colonial birds (Yu. Artukhin, pers. comm.).

\section{Treatment of fox cubs in 1994}

In 1976 E.P.K., M.G. and colleagues took two infected cubs from the island and successfully treated them for mange. Their untreated littermates died. In view of the precariously low population density of Arctic foxes on Mednyi for the last 15 years and encouraged by the success of treating the two cubs in 1976, we decided that conservation criteria justified and necessitated veterinary intervention to treat dying cubs with the aim of increasing their chances of survival and, thereby, population density. From June to September 1994, 48.3 per cent of fox cubs in the southern half of Mednyi were captured by hand, or with nets or box traps, and those diagnosed with mange were treated. Infected cubs were treated with Alugan Spray (Bromociclen; Hoechst Veterinar $\mathrm{GmbH}$ ) and Ivermectin (Ivomec, MSDAgvet) injections ( $1 \mathrm{ml} 0.3$ per cent per 1 $\mathrm{kg}$ of weight). Severe cases were injected with an immuno-adjuvant (Gemma-B; 1 EA per 2 $\mathrm{kg}$ weight). The health of treated litters was monitored over 2 weeks. One injection with Ivermectin is known to cause a sharp reduction in the number of imago mites and this improvement persists for c. 1 month (F.I. Vasilevich, pers. comm.). Ideally, a second injection after 2 weeks fully clears the mites but was impractical in this case. In the southern section of the island no sick cubs were untreated, partly because we did not judge this to be ethical, in the face of this conservation crisis, and partly because cubs in the northern section provided an untreated comparison.

Potentially lethal ectoparasite infestations were found in 22 out of $\mathbf{2 8}$ cubs examined. The other six cubs appeared to be healthy.
Twenty-seven cubs were treated with Alugan Spray, of which 20 were also injected with Ivomec. Four severely diseased cubs were injected with the immuno-adjuvant. Although all treated cubs still had severe mange by late August, none had died, in marked contrast to events in 1976 and 1978. We believe that this reduced mortality by late August was due to the veterinary treatment, but we cannot exclude the possibility that 1994 saw coincidental increase in the foxes' resistance to mange, or a decrease in the virulence of mange. Furthermore, as mentioned above, we cannot exclude the possibility of some change in another pathogen. However, in 1995 we were able to survey the southern sector and found that of 58 cubs and 16 adults tagged in 1994, 15.5 per cent of cubs remained as yearlings, whereas 68.8 per cent of adults remained. In 1994, 27 of 58 cubs had been tagged and treated in the southern sector, and by the summer of 1995 survival to adulthood of the treated cubs was at least 19.2 per cent, whereas that of untreated cubs was 12.5 per cent. Although this difference is not statistically significant, we have considered potential sample biases, such as loss of eartags and emigration to the northern sector, which are highly likely to lead to an underestimate of the survival of treated cubs. For example, we suspect that at least one treated cub lost its eartags and two others migrated to the northern sector, while two northern cubs migrated south. Even the small increase in estimated survival of treated cubs caused by these suspicions would lead to a statistically significant increase in over-winter survival of treated cubs. Logistical difficulties prevented us from carrying out a census of the northern sector in 1995, thwarting the comparison between southern and northern sectors, and so we cannot confirm the foregoing suspicions, but they provide grounds for optimism and encourage us to continue the treatment.

\section{Conclusions}

An apparent reduction in summer mortality of cubs treated in 1994 against mange, in contrast 
with heavy summer mortality during previous years when cubs were untreated, may have translated into a marginal increase in yearling survival by the summer of 1995 . We therefore believe it is appropriate, cautiously, to repeat the treatment in the future, meanwhile striving to overcome logistical difficulties in order to mark, and thereafter monitor more fully the survival of, a complete sample of treated and untreated cubs. Aided by the advice of the IUCN/SSC Veterinary Specialist Group, we also hope to screen more fully for other canid pathogens.

Diseases are a natural and widespread factor in population dynamics and, in a small, endemic population, may cause extinction. The Mednyi Arctic foxes are an isolated relict population, that may never have been challenged by mange or other diseases of domestic dogs before the 1970s. Their dramatic decline suggests that they had no natural immunity to the parasite. Strong circumstantial evidence suggests that mange was brought to the island with domestic dogs, further justifying our intervention on the grounds that the disease was not in that sense a 'natural' infection of Mednyi foxes. This story emphasizes the perils of introduced disease to isolated endemic populations (e.g. Macdonald, 1993; McCallum and Dobson, 1995).

Two generalizations arise from the plight of the Mednyi foxes. First, some wild populations are so rare that disease is an ominous threat (and most are rare and fragmented because humans made them that way); second, the most likely source of disease stems from domestic animals (a source nurtured by humans; Macdonald, 1996). An obvious response to such cases would be intervention at two points. First, to tackle the background risk by reducing the numbers of infectious domestic mammals and/or to focus directly on the imperilled wildlife, perhaps by treating or vaccinating them. On Mednyi, the first option is no longer open - the dogs that brought mange to the island no longer visit. Intervention requires evaluating the balance of factors (Macdonald, 1995) and we concluded that in this case it was justified. The subspecies of Arctic foxes on Mednyi had lived there in iso- lation since the Bering land-bridge melted beneath its feet. Isolated, that is, until seafaring fur trappers, having decimated their numbers by the early 1970s, departed with a Parthian shot in the form of the Otodectes mite dropped from their dogs. The resulting disease appears to have catapulted cub mortality to over 90 per cent. True, extinction can be natural; true, mange is a natural disease of foxes; true, left to their own devices the foxes might just evolve a gene to provide them with the immunity they seemingly lack. On the other hand, it was humans who overharvested the entire subspecies, humans who introduced the dog-borne mange; humans, ultimately, who were responsible for making it a fair bet that a protracted debate on the ethics of intervention would last longer than Mednyi's foxes. It is too soon to know whether our intervention has increased the Mednyi island foxes' chance of being there to greet the next millennium, but there is no sign that it has lessened the odds.

\section{Acknowledgements}

The 1976 and 1978 surveys were financed by Moscow State University and the 1994-1995 survey was funded by the People's Trust for Endangered Species (UK), the Actual Biology Foundation (Russia), Fauna \& Flora International (UK), International Science Foundation (Grant N NB 2000), and Tusk Force (UK). We wish to thank Vladimir Smirin, Nikita Ovsjanikov and students who contributed to demographic records for 1976 and 1978. Thanks are also due to D. FeddersenPetersen, A.V. Generalov and F.I. Vasilevich, who gave us veterinary preparations. Parasites were identified by Ovsukova of the Central Veterinary Laboratory of the Ministry of Agriculture of Russia, A. Majorov of the National Institute of Fur Farming and A. Khrustalev. We thank A.V. Zimenko for his support and contributions throughout the study, together with support in the field by Yu. Artukhin, A. Boltnev, A. Burdin, A. Burkanov, A. Stegaro, V. Vertjankin and especially our field assistants Dmitrii Glasov and S. V. Zagrebelnyi. We are particularly grateful to Mike Woodford of the IUCN/SSC Veterinary Specialist Group, with whom we have consulted closely. 


\section{References}

Chelnokov, F.G. 1982. Number of blue Arctic fox on the Mednyi south-eastern fur seal rookery. Voprosi geografii Kamchatki, 1 (8), 91-92. (In Russian.)

Danell, K. and Hoernfeldt, B. 1987. Numerical responses by populations of red fox and mountain hare during an outbreak of sarcoptic mange. Oecologia, 73, 533-536.

Geptner, V.G. and Naumov, N.P. 1967. Mammals of the USSR. Vol. 2, Part 1. Vishaja Shola, Moscow.

Ginsberg, J.R. and Macdonald, D.W. 1990. Foxes, Wolves, Jackals and Dogs: An Action Plan for the Conservation of the Canids. IUCN, Gland, Switzerland.

Iljina, E.D. 1950. Island Fur Farming. Mesdunarodnaja kniga, Moscow.

Kruchenkova, E.P. 1991. Ontogeny of social behaviour and parent-offspring relations in the arctic fox. PhD thesis, University of Moscow.

Kruchenkova, E.P. and Goltsman, M.E. 1994. Parental behaviour in Commander Arctic foxes. Zool. Journal, 73 (5), 88-101.

Lindstrom, E. and Morner, T. 1985. The spreading of sarcoptic mange among Swedish red foxes in relation to fox population dynamics. Rev. Ecol. 40, 211-216.

Lindstrom, E., Andren, H., Angelstam, P., Cederlund, G., Hoernfeldt, B., Jaederberg, L., Lemnell, P-A., Martinsson, B., Skoeld, K. and Swanson, J.E. 1994. Disease reveals the predator: sarcoptic mange, red fox predation, and prey populations. Ecology, 75, 1042-1049.

Macdonald, D.W. 1992. The Velvet Claw: A Natural History of the Carnivores. BBC Books, London.

Macdonald, D.W. 1993. Rabies in wildlife: a conservation problem. Onderstepoort Journal of Veterinary Research, 60, 351-355.

Macdonald, D.W. 1995. The case for intervention. $B B C$ Wildlife Magazine, January 1995, 14 (1), 64.

Macdonald, D.W. 1996. Dangerous liaisons and diseases. Nature, 379, 400-401.

Mayr, E. 1963. Animal Species and Evolution. Harvard University Press. Cambridge, MA.
McCallum, A.A. and Dobson A. 1995. Detecting disease and parasite threats to endangered species and ecosystems. TREE, 10 (5), 190-194.

Naumov, N.P., Goltsman, M.E., Kruchenkova, E.P., Ovsijnikov, N.G. and Smirin, V.M. 1981. Social behaviour of Arctic fox on the Mednyi Island. In Ecology, Population Organisation, and Communicative Processes in the Mammals (ed. N. P. Naumov), pp. 31-75. Nauka, Russia.

Ovsjanikov, M.G., Goltsman, M.E., Kruchenkova, E.P. and Smirin, V.M. 1982. Status of the arctic fox population on the Mednyi Island. In Conservation of Mammals in the Far East, pp. 153-154. Vladivostok.

Shmidt O.A. 1991. Prospects for the economical use of the Comander Islands mineral resources. In Natural Resources of Commander Islands (ed. V. E. Sokolov), pp. 30-36. Moscow State University Press, Moscow.

Steller, G.W. 1793. Reise von Kamschatka nach America mit dem Commandeur Capitan Bering. Ein Pendant $z u$ dessen Beschreibung von Kamschatka. Iochan Zacharias Logan, St Petersburg.

Suvorov, E.K. 1912. Commander Islands and Trapping on Them. GUZiZ, St Petersburg.

Vladimirov, V.A. 1991. Basic biostatistic parameters of fur seal populations in USSR in 1958-90. In Science Researching of Sea Mammals on North Pacific in 1989-1990 (compiler L. A. Popov), pp. 165-19. VNIRO, Moscow.

Wayne R.K., George, S.B., Gilbert, D., Collins, P.W., Kovach, S.D., Girman, D. and Lehman, N. 1991. A morphologic and genetic study of the island fox, Urocyon littoralis. Evolution, 45, 1849-1868.

Zalkin, V.I. 1944. Geographical variability in the skull structure of the Eurasian polar fox. Zool. Journal, 23 (4), 156-169.

M. Goltsman, Faculty of Biology, Moscow State University, Moscow 119899, Russia.

E. P. Kruchenkova and D.W. Macdonald, Wildlife Conservation Research Unit, Department of Zoology, University of Oxford, South Parks Road, Oxford OX1 3PS, UK. 